\title{
PROBLEMAS COMPETENCIALES DERIVADOS DE LA LEY 40/2010 DE ALMACENAMIENTO GEOLÓGICO DE DIÓXIDO DE CARBONO ${ }^{1}$
}

\author{
ISABEL CARO-PATÓN CARMONA \\ Profesora titular de Derecho Administrativo \\ Menéndez\&Asociados Abogados \\ icaro@menendez-abogados.com
}

Recibido: 5 de enero de 2013 / Aceptado: 7 de marzo de 2012

RESUMEN: El sistema de distribución de competencias establecido por la Ley 40/2010, de 29 de diciembre, de Almacenamiento Geológico de Dióxido de Carbono, que se caracteriza porque el Estado se atribuye competencias ejecutivas importantes, resulta complejo y difícil de justificar en los títulos constitucionales. El conflicto competencial ya ha sido planteado por tres CC. AA. (Aragón, Cataluña y Galicia) ante el Tribunal Constitucional y, sin perjuicio de la resolución que eventualmente recaiga, a simple vista no es fácil entender por qué el Estado se atribuye la competencia para otorgar las concesiones que la Ley regula, cuando tanto en materia de medio ambiente como de minas carece de competencias de ejecución. Además, el análisis de las competencias en juego manifiesta una problemática más amplia que la citada Ley suscita que tiene que ver con las dificultades de coordinación que pueden advertirse y que, sin duda, determinarán una pérdida de eficacia administrativa.

RESUM: El sistema de distribució de competències establer per la Llei 40/2010, de 29 de desembre, d'emmagatzematge geològic de diòxid de carboni, que es caracteritza perquè l'Estat s'atribueix competències executives importants, resulta complex i difícil de justificar en els títols constitucionals. El conflicte competencial ja ha estat plantejat per tres comunitats autònomes (Aragó, Catalunya i Galícia) davant del Tribunal

\footnotetext{
${ }^{1}$ Quiero agradecer a Elisa Moreu Ballonga, experta en derecho minero, los comentarios y las aclaraciones que me ha hecho para la redacción final de este artículo.
} 
Constitucional i, sense perjudici de la resolució que recaigui en el seu cas, a simple vista no és fàcil entendre perquè l'Estat s'atribueix la competència per atorgar les concessions que la Llei regula, quan tant en matèria de medi ambient com en la de mines està mancat de competències executives. A més, l'anàlisi de les competències en joc posa de manifest una problemàtica més àmplia que la que la Llei suscita., que té a veure amb les dificultats de coordinació que poden detectar-se i que, sense dubte, donaran lloc a una pèrdua d'eficàcia administrativa.

ABSTRACT: The distribution of powers, according with the Spanish Act 40/2010, of December 29th, regulating the geological storage of Carbon Dioxide, is characterized by a strong intervention of central government. This is very difficult to justify according with the Constitution. Three autonomous communities (Aragon, Catalonia and Galicia) have presented lawsuits before the Constitutional Court on this subject. Before the Court gives its opinion, it can be stated that it is difficult to understand the intervention of central government in executive matters in this domain. This is because Spanish Constitution and the Statutes of autonomous communities give executive power in the areas of environmental protection and mining to the latter. Moreover, the commented Act presents difficulties at the level of coordination. Therefore, a loss of efficacy is foreseeable.

PALABRAS CLAVE: Distribución competencial — Medio ambiente — Minas — Almacenamiento geológico de $\mathrm{CO}_{2}$ — Directiva 2009/31.

PARAULES CLAU: Distribució competencial — Medi ambient — Mines — Emmagatzematge geològic de $\mathrm{CO}_{2}$ — Directiva 2009/31.

KEYWORDS: Distribution of Powers - Environmental Protection - Mining Geological Storage of $\mathrm{CO}_{2}$ - Directive 2009/31. 
SUMARIO: I. Introducción. II. Discusión: 1. Planteamiento comunitario. 2. Descripción de la distribución competencial: primeras valoraciones. 3. Títulos utilizados. III. Opciones legales que provocan el problema competencial de fondo: 1. El complejo sistema de intervención administrativa instaurado; el déficit de técnicas de coordinación. 2. Inaplicabilidad de la Ley de Minas; traslación del régimen competencial de los hidrocarburos. 2.1. Paradójica aplicación supletoria del reglamento de la Ley de Minas. 2.2. ¿Abandono del sistema de reservas de la Ley de Minas? 3. Urbanismo y almacenes de $\mathrm{CO}_{2}$. 3.1. Concesiones y permisos urbanísticos. 3.2. La limitada competencia autonómica para prohibir almacenes en zonas de su territorio. IV. Conclusiones.

\section{INTRODUCCIÓN}

La Ley 40/2010, de 29 de diciembre, de Almacenamiento Geológico de Dióxido de Carbono (en adelante, LAGDC), por la que se traspone al ordenamiento jurídico español la Directiva 2009/31, de 23 de abril, de mismo nombre (BOE de 30 de diciembre), ha adoptado algunas decisiones conflictivas en lo competencial. Desde la propia lectura de la exposición de motivos de la Ley, ello resultaba bastante claro dado que dedicaba una extensa justificación (en algún punto difícilmente comprensible) a la atribución de funciones para autorizar almacenamientos singulares al Estado mediante el otorgamiento de las concesiones de almacenamiento que la Ley regula.

En el Boletín Oficial se publicarían, algunos meses después de la aparición de la Ley (20 de abril y 31 de octubre de 2011), tres recursos de inconstitucionalidad planteados por las comunidades autónomas de Aragón, Cataluña y Galicia ${ }^{2}$. En la tabla que se recoge al final de este precepto se singularizan, a modo de curiosidad, los preceptos impugnados por cada una de ellas.

Que también en esta materia exista un conflicto no es fácil de entender, dado el carácter singular de la regulación, que se refiere a una técnica que tal vez no llegue a aplicarse nunca en los respectivos territorios. Hoy por hoy, no se ha demostrado que el almacenamiento geológico sea una tecnología razonable, habida cuenta del alto coste de las instalaciones y de la incertidumbre sobre sus efectos ambientales. A medio plazo, y en tanto en cuanto no suba el precio de los derechos de emisión de gases de efecto invernadero, serán muy raras las iniciativas privadas para almacenar carbono. Y, de

\footnotetext{
${ }^{2}$ Aragón fue la primera comunidad autónoma en recurrir: el Pleno del Tribunal Constitucional, por providencia de 12 de abril de 2011, admitió a trámite el recurso contra los artículos que se especifican en la tabla final. Cataluña y Galicia pidieron la aplicación del artículo 33.2 LOTC, que amplía el plazo de interposición del recurso cuando se inicien las negociaciones para encontrar una posición común, siempre que se reúna la respectiva Comisión Bilateral de Cooperación Administración General del EstadoComunidad Autónoma. No ha habido resultado positivo en ninguno de los dos casos. Dos providencias del Pleno del Tribunal Constitucional de 18 de octubre de 2011 admiten ambos recursos. Los artículos impugnados también se recogen en la citada tabla. En el caso de Cataluña, se ha emitido un dictamen del Consejo de Garantías Estatutarias (Dictamen 2/2011, de 21 de marzo).
} 
hecho, los dos únicos proyectos que existen en España cuentan con financiación comunitaria $^{3}$. Por eso (siendo un pastel tan pequeño), ¿por qué pelearse por las competencias?

Pues bien, a poco que se escarbe en los debates parlamentarios, aparecen pequeñas pistas.

Para el Estado, conservar las competencias era importante habida cuenta de que se había optado por hacer una trasposición plana de la Directiva (si se permite la expresión) ${ }^{4}$. La LAGDC, y en esto había acuerdo entre el PSOE y el PP, se limitaba a establecer un marco para que cualquier iniciativa privada pudiera ser analizada, lo que cercenaba las posibilidades autonómicas para descartar u obstaculizar proyectos ${ }^{5}$.

Es decir, la LAGDC establece un marco procedimental (ni siquiera un procedimiento, porque muchos aspectos dependen de un futuro reglamento y de normas autonómicas reguladoras de su intervención) para que distintos órganos administrativos supervisen proyectos privados, soslayando la adopción de una política específica ${ }^{6}$. Y, por esto, se debió considerar prudente que fuera la Administración central quien asumiera la competencia decisoria final sobre todos y cada uno de los almacenes de carbono.

\footnotetext{
${ }^{3}$ Existe un instrumento financiero específico comunitario, regulado por el Reglamento 663/2009 del Parlamento Europeo y del Consejo, de 13 de julio de 2009, por el que se establece un programa de ayuda a la recuperación económica mediante la concesión de asistencia financiera comunitaria a proyectos del ámbito de la energía. GÁMEZ MEJÍAS, M., "El marco jurídico del almacenamiento geológico profundo de dióxido de carbono en el contexto de la lucha contra el cambio climático. Perspectivas y reflexiones tras la trasposición al derecho interno”, Revista Aranzadi de Derecho Ambiental, 20/2011, p. 17 de la versión en línea, indica que la legislación "puede quedar como una carcasa vacía de todo contenido si el avance tecnológico (o los intereses económicos) demuestra la inviabilidad de la captura o se encuentra una mejor solución al problema”.

${ }^{4}$ Que la trasposición se limita a copiar la Directiva sin más es un hecho destacado por los autores que han hecho un análisis singular de la Ley. Vid., en particular, ALENZA GARCÍA, J. F., "El nuevo régimen legal del almacenamiento geológico del dióxido de carbono”, Revista de Administración Pública, núm. 185 (2011).

${ }^{5}$ Las palabras del Sr. Valín Alonso, del Partido Popular, ilustran bien la idea que se contiene en el texto: "Es una obligación de todos poner a disposición de los industriales y de los emprendedores españoles un instrumento legal que permita avanzar en todos los inicios, sobre todo en lo que son las actividades de reconocimiento de esa materia”. (Cfr. DS del Senado, Comisiones, núm. 439, de 23 de noviembre de 2010).

${ }^{6}$ Por utilizar dos países de contraste: en Reino Unido se ha tomado la decisión de fomentar el almacenamiento para aprovechar las grandes oportunidades que ofrecen las estructuras geológicas del mar del Norte; en Alemania, en cambio, se ha tenido que bregar con una opinión pública muy beligerante que ve en esta técnica un obstáculo al desarrollo de fuentes de energía renovables. Vid. "Case studies on the implementation of Directive 2009/31/EC on the geological storage of carbon dioxide: Germany", Carbon Capture Legal Programme, UCL Faculty of Laws, Centre for Law and Environment, KRÄMER, L., 2011 (www.ucl.ac.uk/cclp, última visita en marzo de 2012).
} 
Lo que nadie discutió, y esto también muestra el interés del Estado por la técnica, era si el complejo sistema de colaboración interadministrativa implantado, con intervención de cuatro órganos distintos (toman decisiones vinculantes los órganos de minas o industria y los de medio ambiente tanto del Estado como de la comunidad autónoma), resultaría una rémora para cualquier iniciativa al respecto.

En relación con el tema competencial, llama la atención que las Cortes Generales (o más en particular el Senado, en cuanto cámara de representación territorial) no discutieran si el proyecto de ley remitido al Congreso por el Gobierno estaba de facto permitiendo que el planificador territorial (autonómico o local) restringiera la instalación de almacenes en su suelo, en el sentido admitido por la Directiva 2009/31. Pues, en efecto, su artículo 4.1 habilitaba a los Estados para prohibir el almacenamiento total o parcialmente en su territorio y hubiera sido compatible con la norma comunitaria que esta decisión correspondiese a las comunidades autónomas, en ejercicio de su competencia de ordenación territorial o de protección del medio ambiente ${ }^{7}$. De la tramitación parlamentaria solo cabe destacar que se rechazó, por amplísima mayoría, la enmienda a la totalidad planteada por IU-ICV y el BNG, que solicitaba la devolución del proyecto al Gobierno ${ }^{8}$.

Desde la piel de las comunidades autónomas impugnantes no es fácil entender por qué les interesa asumir plenamente una competencia (esto es, la resolución final), cuando en la LAGDC se crea un marco de colaboración interadministrativa que, a primera vista (luego profundizaremos sobre ello), parece suficiente para que las regiones puedan intervenir en la toma de decisiones. Además, en la LAGDC había un elemento de equilibrio, que podría justificar las competencias estatales, consistente en que,

\footnotetext{
${ }^{7}$ La posibilidad de que los planes territoriales restrinjan la implantación de depósitos de $\mathrm{CO}_{2}$ se encuentra en la disposición adicional primera del proyecto de Ley (apartado 3). Esta disposición pasó literalmente a la Ley, sin que consten en los diarios de sesiones debates parlamentarios sobre las dificultades que plantea su interpretación y a las que nos referimos más abajo.

${ }^{8}$ Esta enmienda fue descartada por 327 votos de los 342 que fueron emitidos (hubo 9 votos a favor de la enmienda y 6 abstenciones). El Sr. Herrera, de IU-ICV, apoyó su oposición total a la Ley con el siguiente discurso: " $\mathrm{El}$ almacenamiento de $\mathrm{CO}_{2}$ o de carbono es el atajo para no tener que hacer los deberes que se tienen que hacer en materia energética. Es la tentación que expresa el Gobierno, y creo que también la mayoría de la Unión Europea, hacia las respuestas fáciles y baratas por delante de las propuestas a medio y a largo plazo que representen la modernización energética. Por eso presentamos esta enmienda a la totalidad, porque entendemos que la opción es técnica, pero lo que expresa es la renuncia a un cambio de modelo y a una lucha contra el cambio climático que signifique una reducción efectiva de emisiones de gases de efecto invernadero”. (DS Congreso de los Diputados, Pleno y Dip. Perm., núm. 175, de $17 / 06 / 2010)$.
} 
transcurridos 20 años desde el cierre del depósito, la responsabilidad por daños pasaría al Estado (artículo 24 dictado en trasposición del artículo 18 de la Directiva).

Como de la intervención en el Senado del Sr. José María Mur Bernad (senador del PAR Aragón) se puede colegir qué aspectos preocupaban a las comunidades autónomas impugnantes, nos ha parecido oportuno reproducir literalmente sus palabras:

"En definitiva, sus señorías saben que es una ley bastante técnica en la que, evidentemente, se parte de una serie de conocimientos geológicos de los terrenos, y precisamente por eso a nosotros, a la Comunidad Autónoma de Aragón, nos afecta muy directamente, ya que la geología del valle del Ebro ofrece numerosos enclaves próximos a una central térmica. Además, los expertos nos advierten de que las tecnologías de captura y almacenamiento del $\mathrm{CO}_{2}$ serán vitales para la supervivencia de la minería española y, por tanto, de la aragonesa, y también para las centrales térmicas que se encuentran, como digo, en este caso en el territorio aragonés, dado que la geología de nuestro territorio parece que resulta idónea, desde el punto de vista de los técnicos, para estos almacenes de $\mathrm{CO}_{2}$. Por tanto, no nos resulta ajeno e incide muy directamente en lo que puede suceder en nuestro territorio.

[...]

En particular, rechazamos que las concesiones de almacenamiento geológico de dióxido de carbono, siendo una competencia claramente ejecutiva, se la reserve el Estado de forma injustificada, sobre todo cuando se atribuye a las comunidades autónomas los permisos de investigación, la función de inspección y la aprobación del plan de seguimiento y del plan provisional de gestión posterior al cierre, y hace responsables a las comunidades autónomas del seguimiento de las medidas correctoras una vez cerrado el lugar de almacenamiento y hasta la transferencia de dicha responsabilidad. Es decir, el Estado se reserva el poder de decidir la concesión y las comunidades autónomas el cometido de supervisar su correcto funcionamiento, que es lo que realmente genera gasto y a su vez responsabilidad. No hay ninguna razón técnica que justifique que la competencia ejecutiva sobre la concesión del almacenamiento geológico de dióxido de carbono se la tenga que reservar el Estado.

El Estado pretende justificar la competencia para decidir la concesión teniendo en cuenta que de ella pueden depender, en su caso, la autorización y el establecimiento de grandes instalaciones de combustión. Sin embargo, ello debe rechazarse porque la concesión del almacenamiento no es discrecional ni 
estratégica, sino reglada al cumplimiento de unos requisitos técnicos de naturaleza geológica y de protección del medio ambiente, es decir, no sirve solamente el procedimiento para las grandes instalaciones de combustión, sino que tiene que darse la segunda condición técnica de naturaleza geológica. Además, en el artículo 7 del proyecto ya se admite que las autorizaciones, permisos y concesiones objeto de la Ley lo serán sin perjuicio de aquellas otras autorizaciones que los trabajos, construcciones e instalaciones necesarios para su desarrollo pudieran requerir.

Para mayor contradicción, en esta ley nos encontramos con que actualmente y hasta que entre en vigor la ley que estamos tramitando, la competencia ejecutiva se está ejerciendo por las comunidades autónomas en aplicación de la vigente Ley 22/1973, de 21 julio, de Minas, en su disposición transitoria primera. Por tanto, con todas estas enmiendas pretendemos que en la mayor parte de los casos en los que en el proyecto se habla del Ministerio de Industria, Turismo y Comercio, se hable de las comunidades autónomas”.

Saliendo de los argumentos políticos y entrando en un plano jurídico, se ha de reconocer que la decisión del Estado español resulta complicada de justificar en lo competencial porque, tanto si se reconduce esta actividad al medio ambiente como a las minas o a la energía, la gestión de ambas materias corresponde a las comunidades autónomas (cfr. art. 149.1.23 y 149.1.25).

Lógicamente, más adelante discutiremos qué encuadramiento competencial es el más adecuado. Por el momento nos conformaremos con adelantar que en el ámbito comparado, y en concreto en países de fuera de la UE donde está regulada esta materia tan futurista, las normativas siempre atribuyen la decisión a los organismos de energía o hidrocarburos ${ }^{9}$. Y, por ello, parece un poco artificial que se justifiquen las competencias estatales, como se ha hecho, en el título relativo a las bases de la planificación económica (art. 149.1.13). No creemos que sea del todo cierto que esto se apoye en el gran impacto que esta normativa puede tener en la economía, porque de momento la repercusión es nimia ${ }^{10}$.

\footnotetext{
${ }^{9}$ GÁMEZ MEJÍAS, M., “El marco jurídico...”, cit., p. 9 de la versión en línea.

${ }^{10}$ Cfr. en el Diario de Sesiones del Senado (Comisiones, núm. 439, de 23 de noviembre de 2010) las declaraciones que hizo la Sra. Iranzo Sánchez, del Grupo Parlamentario Socialista: "Si partimos de la afirmación de que el almacenamiento de carbono es de interés nacional estratégico, los títulos competenciales, senador Mur, son los de los artículos 149.1.13. ${ }^{a}, 23 .{ }^{a}$ y 25. ${ }^{a}$ de la Constitución por una razón, por el gran impacto que esta normativa tiene en nuestra economía". En el mismo Diario de Sesiones también el Sr. Valín Alonso, del Grupo Parlamentario Popular, defendió la competencia estatal, invocando el artículo 149.1.23. ${ }^{\text {a }}$ de la Constitución.
} 


\section{DISCUSIÓN}

\section{Planteamiento comunitario}

Para almacenar $\mathrm{CO}_{2}$, y de acuerdo con la Directiva 2009/31, existen dos momentos en los que ha de intervenir el poder público.

El primero de ellos es el "permiso de exploración”, que sirve para habilitar a las empresas a realizar tareas de investigación para seleccionar ubicaciones geográficas adecuadas (art. 5). Esta intervención, de acuerdo con la Directiva 2009/31, no siempre es necesaria, pues puede ser que las zonas aptas para el almacenamiento fueran conocidas y estuvieran previamente seleccionadas.

El segundo momento consiste en el otorgamiento del "permiso de almacenamiento", por el que el particular recibe el derecho a utilizar en exclusiva un depósito durante un período de tiempo dado (art. 6). Por la incertidumbre científica, y para facilitar la inversión privada, tras el cierre del almacén la responsabilidad por riesgos se traslada a las autoridades competentes de los Estados (art. 18) ${ }^{11}$.

Los conflictos competenciales planteados derivan de que la LAGDC atribuye al Estado funciones determinantes relacionadas con el otorgamiento de los dos permisos o, en definitiva, con la selección de zonas y con el uso de los depósitos. Que el Estado sea oído o intervenga en el procedimiento del permiso de almacenamiento resulta en cierto sentido inevitable, habida cuenta de que la propia Directiva permite a la Comisión emitir informes (no vinculantes) sobre cualquier proyecto de almacenamiento (art. 10) ${ }^{12}$. Y, con cierta ironía, cabe decir que si la Comisión informa, ¡cómo no va a participar el Estado!

\footnotetext{
${ }^{11}$ GÁMEZ MEJIAS, óp. cit., declara que este desplazamiento es la única forma de otorgar seguridad jurídica a altas inversiones en actuaciones pioneras cuyos riesgos futuros son imprevistos.

${ }^{12}$ Ha explicado SANZ RUBIALES, I., "El almacenamiento geológico de dióxido de carbono en la directiva 2009/31, de 31 de abril”, Revista Aranzadi de Derecho Ambiental, núm. 19/2011, que "la Comisión, en el proyecto de marco normativo del secuestro de carbono (previo a la propuesta de Directiva), se otorgaba a sí misma competencias para aceptar o rechazar las propuestas de los Estados sobre el otorgamiento de permisos; pero este planteamiento generó inquietud en algunos interlocutores, por razón de su difícil encaje con los principios de subsidiariedad y proporcionalidad, lo que llevó a mantener una evaluación (dictamen) en manos de la Comisión, pero garantizando a los Estados la última palabra” (cfr. la exposición de motivos de la propuesta de Directiva, n. 2).
} 


\section{Descripción de la distribución competencial: primeras valoraciones}

El interminable artículo 5 LAGDC se ocupa de la distribución competencial, para señalar las competencias del Ministerio de Industria (apdo. 1), las del Ministerio de Medio Ambiente (apdo. 2) y las de las comunidades autónomas (apdo. 3).

Según la LAGDC, corresponde al Ministerio de Industria, Turismo y Comercio: a) “Otorgar los permisos de investigación previstos en esta ley cuando afecten al ámbito territorial de más de una comunidad autónoma o al subsuelo marino y resolver, de acuerdo con el artículo 6, los conflictos por concurrencia de derechos que afecten a los mismos”; b y c) “Otorgar [y revocar] las concesiones de almacenamiento previstas en esta ley y resolver los conflictos por concurrencia de derechos que afecten a las mismas"; d) “Comprobar la solvencia financiera del titular de una concesión de almacenamiento y la preparación técnica del personal que desarrollará sus funciones en los lugares de almacenamiento”; e) “Garantizar que no se dan usos incompatibles en los lugares de almacenamiento, en el ámbito de sus competencias, y coordinarse con otras administraciones para garantizar el mismo objetivo"; f) "Resolver los conflictos relativos al acceso a las redes de transporte y lugares de almacenamiento"; g) "Crear y mantener un registro que reúna la información relativa a permisos de investigación, concesiones de almacenamiento y lugares de almacenamiento cerrados, recabando la información pertinente de otras Administraciones públicas”; h) “Aprobar, como órgano sustantivo, los proyectos de instalaciones de estos almacenamientos de acuerdo con lo establecido en la normativa vigente"; e i) "La inspección de los lugares de almacenamiento situados en el subsuelo marino. En caso de observar irregularidades significativas o fugas, se asegurará que el titular de la concesión adopte las medidas correctoras necesarias, y en caso de que lo estime necesario, las adoptará por sí misma”. En el apartado 2 se singularizan las competencias del Ministerio de Medio Ambiente: a) informar, en los términos previstos en esta ley, la concesión de los permisos de investigación y las concesiones de almacenamiento, así como formular la declaración de impacto ambiental; b) ejercer las funciones de seguimiento y supervisión de los almacenes que hubieran sido cerrados, así como en los supuestos en los que se haya producido la transferencia de responsabilidad a la Administración general del Estado, en los términos previstos en esta ley; c) proponer al Consejo de Ministros la transferencia de responsabilidad sobre los lugares de almacenamiento cerrados; y d) crear y mantener un registro de lugares de almacenamiento cerrados. 
Por último, el listado de competencias autonómicas que contiene el artículo 5.3 es el siguiente: “a) Otorgar los permisos de investigación previstos en esta ley cuando no excedan del ámbito territorial de una comunidad autónoma y resolver, de acuerdo con el artículo 6, los conflictos por concurrencia de derechos que afecten a los mismos. b) Informar las solicitudes de concesión de almacenamiento. c) Aprobar el plan de seguimiento y el plan provisional de gestión posterior al cierre. d) Establecer un sistema de inspecciones en los lugares de almacenamiento. e) Asegurarse de que en caso de irregularidades significativas o fugas, el titular de la concesión adopte las medidas correctoras necesarias, y en caso de que lo estime necesario, adoptarlas por sí misma. f) Responsabilizarse del seguimiento y de las medidas correctoras una vez cerrado un lugar de almacenamiento y hasta la transferencia de responsabilidad”.

En definitiva, lo que se infiere de los párrafos anteriores es que el Estado se reserva las competencias sobre permisos de investigación intercomunitarios ${ }^{13}$ y en el subsuelo marino y el otorgamiento y los efectos (modificación, revocación y resolución de conflictos) de las concesiones de almacenamiento. La asunción de la competencia sustantiva arrastra, y sobre ello hay jurisprudencia reiterada, otras dos. En primer lugar, la correspondiente a la evaluación ambiental (SSTC 13/1998, 101/2006, 1/2012 y 34/2012). Y, en segundo lugar, la correspondiente al régimen sancionador, ya que "la potestad sancionadora no constituye un título competencial autónomo” (por todas, STC 156/1995, FJ 7).

Por su parte, las comunidades autónomas otorgarán, en su caso, los permisos de investigación (esto es, para los supuestos en que no se conozcan los emplazamientos de los almacenes) y se encargarán plenamente, y sin perjuicio de posibles inspecciones estatales, del plan de seguimiento ambiental de la concesión de almacenamiento.

El artículo 28 de la Ley también crea, en pura trasposición de la Directiva, un registro administrativo en el que el Estado inscribirá todos los permisos y concesiones. El modo de regular esta cuestión no ha sido cuestionado, dado que el artículo 28.1 LAGDC recoge los requisitos de la jurisprudencia constitucional que existe al respecto desde la STC 197/1996, FJ 12 y que consiste, en definitiva, en que las inscripciones en el

\footnotetext{
${ }^{13}$ En algún caso el TC no ha admitido la supraterritorialidad como criterio justificativo de la competencia estatal: STC 329/1993 sobre contaminación atmosférica.
} 
registro estatal de permisos otorgados por las comunidades autónomas se practicarán de acuerdo con la información que estas remitan ${ }^{14}$.

Las impugnaciones autonómicas recaen sobre muchos preceptos y de nuevo nos remitimos a la tabla final, si bien en su mayor parte se vinculan a la decisión estatal de asumir las competencias sobre las concesiones de aprovechamientos, ordenar el acceso de terceros y asumir la responsabilidad tras el cierre ${ }^{15}$.

\section{Títulos utilizados}

En la DF 11 de la LAGDC se hacen explícitos los títulos competenciales estatales utilizados para dictar la Ley, que son:

“Esta ley tiene carácter básico al amparo del artículo 149.1. 23. a de la Constitución Española, que atribuye al Estado la competencia para dictar la legislación básica en materia de protección del medio ambiente con las siguientes excepciones:

a) Los artículos 10, 11, 13, 14, 15, 24 y 25 se dictan al amparo de las competencias atribuidas en el artículo 149.1.13. a de la Constitución Española.

b) Los artículos 3, 6, 7, 8, 9, 16, 17, 26 y 27 se dictan al amparo de las competencias atribuidas en el artículo 149.1.25. ㄹ de la Constitución Española”.

Repárese que esta disposición se apoya en tres títulos del 149.1, ninguno de los cuales atribuye al Estado competencias de ejecución: el número 23. se refiere a "legislación

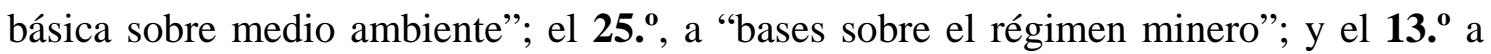
“bases y coordinación de la planificación general de la actividad económica”. En realidad, y como ya hemos avanzado, es este último el que sirve para apoyar las competencias ejecutivas más importantes del Ministerio de Industria (las concesiones de almacenamiento), porque sobre la interpretación del 23 y el 25 hay una jurisprudencia

\footnotetext{
${ }^{14}$ STC 223/2000, FJ 10: “«Es constitucionalmente posible la creación de un registro único para todo el Estado que garantice la centralización de todos los datos a los estrictos efectos de información y publicidad» y, a este fin, «fijar las directrices técnicas y de coordinación necesarias» para garantizar su centralización, si bien «el Estado debe aceptar como vinculantes las propuestas de inscripción y de autorización o de cancelación y revocación que efectúen las Comunidades Autónomas que ostentan las competencias ejecutivas en la materia. Pues si las facultades del Estado están circunscritas a la potestad de normación para la creación de un registro único, estas otras facultades, de índole ejecutiva, exceden de su ámbito de actuación competencialmente posible» (STC 243/1994, FJ 6) (STC 197/1996, FJ 12)”.

${ }^{15}$ Artículos 6, 10, 11, 13, 15, 19, 23, 24, 25, 26 у 27.
} 
constitucional bastante restrictiva con respecto a las funciones estatales (respectivamente, se pueden citar las SSTC 33/2005 y 197/1996) ${ }^{16}$.

Aunque es habitual utilizar diversos títulos, se aprecia que la redacción de la DF trasluce las dificultades del legislador para encontrar títulos competenciales suficientes para las decisiones adoptadas. Y, además, hay dos cosas que, aunque no tienen demasiada importancia, resultan un poco extrañas:

En primer lugar, que se indique que una ley de 38 artículos es legislación básica de medio ambiente cuando la mitad de los preceptos se apoyan en otras materias (en total entre las letras a) y b) suman 16 preceptos).

En segundo lugar, y sobre todo, que estando el esquema competencial apoyado sobre el sistema de la Ley 34/1998, de 7 de octubre, de Hidrocarburos (LHi) ${ }^{17}$, se aparte de la calificación de preceptos que hace esta ley (nunca impugnada por las comunidades autónomas por razones competenciales), que, con mayor precisión, separa entre legislación plena o general y básica. De hecho, la DF 1, apartado 3 LHi dispone que:

“Los preceptos del Título II relativos a exploración, investigación y explotación de hidrocarburos son de aplicación general, al amparo de lo previsto en el artículo 149.1.13ª $18^{\mathrm{a}}$ y $25^{\mathrm{a}}$ de la Constitución”.

\section{OPCIONES LEGALES QUE PROVOCAN EL PROBLEMA COMPETENCIAL DE FONDO}

1. El complejo sistema de intervención administrativa instaurado; el déficit de técnicas de coordinación

Cuando el Sr. Rubalcaba, del Partido Socialista, explicó el proyecto de Ley en las Cortes Generales (DS del Congreso de los Diputados, Pleno y Diputación Permanente, núm. 175, de 17/06/2010) puso de relieve que la LAGDC instauraba un sistema de colaboración interadministrativa. Sus palabras fueron las siguientes:

\footnotetext{
${ }^{16}$ No consideramos necesario desmenuzar aquí la compleja jurisprudencia constitucional (tampoco la recaída sobre el artículo 149.1.13), porque nos llevaría a matices difíciles de explicar (y, por otro lado, no hay mucho que oponer a los argumentos del Dictamen del Consejo de Garantías Estatutarias de Cataluña, citado en la nota 2 y disponible en cualquier base de datos jurídica).

${ }^{17}$ Así se reconoce abiertamente en la exposición de motivos, apartado III.
} 
“Corresponderá a la Administración del Estado otorgar las concesiones de almacenamiento, y creo que es importante destacar que estas deberán incorporar los planes de seguimiento que previamente hayan aprobado las comunidades autónomas. Por tanto, aunque la concesión se reserva a la Administración General del Estado, una pieza fundamental de la misma, que tiene una gran relevancia desde el punto de vista medioambiental, debe ser aprobada previamente por la Administración autonómica. Las comunidades autonómicas serán también responsables, entre otras cuestiones, de establecer un sistema de inspecciones en los lugares de almacenamiento, de realizar un seguimiento y de establecer las medidas correctoras oportunas. No podemos olvidar que en la medida en que la captura de dióxido de carbono exige una autorización integral desde el punto de vista medioambiental, en esta fase la intervención autonómica es también fundamental. Por último, corresponde de nuevo a la Administración del Estado aprobar el plan definitivo de gestión posterior al cierre y proponer al Consejo de Ministros la transferencia de responsabilidad al Estado. En definitiva, señorías, un régimen en el que la cooperación entre las administraciones públicas va a ser fundamental para el adecuado desarrollo de las tecnologías de captura y almacenamiento, cuya regulación discutimos hoy en esta Cámara”.

Como el objeto de este artículo son los problemas competenciales, es cierto que la LAGDC prevé la intervención de las dos administraciones, pero, sin embargo, es de lamentar que no establezca técnicas específicas de cooperación o coordinación ni que señale el modo en que se resolverán los problemas prácticos que bien pueden vislumbrarse. KRÄMER ya ha destacado problemas de encaje entre el "plan de seguimiento” y la concesión ${ }^{18}$. Falta en la Ley indicar cómo se integra en la concesión estatal (si el Estado puede llevar a cabo controles de legalidad y/o oportunidad sobre este) o, en su caso, cuál es la naturaleza del plan adoptado por la comunidad autónoma. Al respecto y desde una perspectiva procedimental, el plan sin concesión bien puede ser un acto de trámite no cualificado, dado que solo tiene sentido en la medida en que se otorgue la concesión y se integre en esta en los términos dispuestos por el Estado (art. 107.1 de la Ley 30/1992). Estos aspectos podrían haber sido concretados por la Ley ya que encajarían en la legislación básica de procedimiento administrativo (art. 149.1.18),

\footnotetext{
${ }^{18}$ KRAMER, L., “Case studies on the implementation of Directive 2009/31/EC on the geological storage of carbon dioxide: Spain”, University College London, Centre for Law and Environment, Carbon Capture Legal Programme, noviembre 2011, p. 25 (disponible en internet).
} 
y el TC admite que exista legislación básica sectorial (por ejemplo, SSTC 61/1997, para urbanismo, o 149\2011, para aguas) ${ }^{19}$.

Otro problema distinto es el que puede aparecer en casos de fugas, que es un tema, en principio, de competencia autonómica. Aparte de las entregas de derechos de $\mathrm{CO}_{2}$ de acuerdo con la autorización autonómica y el informe de verificación también de las comunidades autónomas, en aplicación de la Ley 1/2005, por la que se regula el régimen de derechos de emisión de gases de efecto invernadero ${ }^{20}$, si como consecuencia de inspecciones u otras causas se detectaran irregularidades o fugas, la competencia autonómica se extenderá a adoptar las medidas necesarias para su corrección (art. 22). Y, en relación con estas medidas, no se prevé la intervención del Estado pese a que las irregularidades puedan incidir o condicionar el régimen concesional. Es parca la previsión legal para estos casos, pues aparte de exigir que las comunidades autónomas informen al Estado de las inspecciones practicadas (art. 21.5), se conforma con permitir que las comunidades autónomas soliciten al Ministerio la revisión o la revocación de la concesión (art. 15), resultando en estos casos preceptiva la audiencia al titular. Es decir, puede ser que se inicie un procedimiento de revisión concesional o revocación una vez que la comunidad autónoma hubiera adoptado medidas correctoras. Además, el sistema implantado de colaboración interadministrativa, que implica que la comunidad autónoma puede solicitar por sí misma la revisión o revocación de la concesión, previa audiencia del titular (es decir, sin necesidad de contar con su consentimiento), sitúa al administrado en una posición innecesariamente compleja. Como no tiene por qué haber acuerdo entre las dos administraciones, se aprecia que la regulación de la colaboración interadministrativa implantada se ha hecho a costa del principio constitucional de eficacia (art. $103 \mathrm{CE})$.

\footnotetext{
${ }^{19}$ También con carácter de normativa básica de procedimiento, y si lo que se quiere, como ya hemos dicho, es apoyar las iniciativas privadas que puedan surgir, habría bastado con prohibir las denegaciones injustificadas de permisos por parte de comunidades autónomas o establecer un informe estatal determinante, realizado con soporte técnico del IGME. También podría haberse establecido con carácter básico la obligación de publicación en el Boletín Oficial de los anuncios de los procedimientos autonómicos que pudieran abrirse, regulando recursos administrativos similares a los de la legislación de contratos (con plazos breves y suspensión automática de la adjudicación en tanto en cuanto un órgano independiente, incluso de carácter nacional, no resuelva el recurso) a interponer por quienes acudan a procedimientos públicos autonómicos y estimen que la resolución resulta discriminatoria.

${ }^{20}$ Vid. CARO-PATON, I., El mercado de derechos a contaminar. Régimen jurídico-público del mercado comunitario de derechos de emisión en España, vol. col. dir. por SANZ RUBIALES, I., Lex Nova 2007, pp. 326ss.
} 
Sin ánimo de exhaustividad, otro aspecto derivado de la artificiosidad de la distribución de responsabilidades es la confusión que puede producirse entre cláusulas concesionales y plan de seguimiento. Y es que se puede dar el caso de que existan infracciones al plan de seguimiento que, a la vez, constituyan incumplimientos de títulos concesionales. Como las consecuencias jurídicas de una y otra cosa pueden ser distintas (solo el incumplimiento de condiciones concesionales esenciales puede determinar su caducidad), también este aspecto debería haber sido aclarado. De nuevo aquí hay que preguntarse dónde queda la eficacia.

Otro problema que debería haberse resuelto, y que también ha sido indicado por KRÄMER, es que no se dice qué autoridad nacional ha de justificar, en su caso, por qué no se sigue el informe determinante de la Comisión a que se refiere el artículo 10.2 de la Directiva $^{21}$. Aunque va de suyo que serán las comunidades autónomas si afecta al plan de seguimiento y al Estado en materias de su competencia, bien podría haberse establecido alguna regla que dotara de certeza al hipotético inversor privado. La experiencia muestra que cuando hay varios órganos administrativos con competencias de distinto tipo en una decisión final última, es inevitable que se dilaten los procedimientos; muy fácil que se diluyan las responsabilidades, y muy complicado para el administrado averiguar en qué mesa está el expediente.

\section{Inaplicabilidad de la Ley de Minas; traslación del régimen competencial de los hidrocarburos}

La entrada en vigor de la LAGDC ha supuesto un giro normativo significativo con respecto a la situación anterior. Hasta su adopción, esta actividad se regía por la Ley 22/1973, de 21 de julio, de Minas (en adelante, LMi), y, en concreto, por las previsiones de la sección B), donde estaba incluido el uso de los depósitos subterráneos (que ya eran de dominio público). Hoy la LMi no es aplicable; la DF 1. a de la LAGDC añade un nuevo apartado cuatro al artículo 1 LMi para indicar que:

“4. La investigación o explotación de estructuras subterráneas para su utilización como almacenamiento geológico de dióxido de carbono se regirá por su legislación específica”.

\footnotetext{
${ }^{21}$ Óp. cit., p. 14.
} 
A esta previsión le siguen varias consecuencias prácticas que merecen ser comentadas.

En primer lugar, que el artículo 3 LAGDC se ha visto obligado a reiterar la pertenencia al dominio público estatal de las estructuras subterráneas naturales y artificiales, algo previsto por la LMi (arts. 2 y 23.3 LMi) ${ }^{22}$. Aunque el Estado apoya esta titularidad en las bases del régimen minero y energético, donde encaja con total facilidad, al reiterar esta pertenencia, Galicia y Aragón han aprovechado para impugnar esta regla preexistente $^{23}$. En mi opinión, de aplicarse aquí la jurisprudencia de la STC 227/1988 sobre la Ley de Aguas, esta impugnación no puede prosperar, máxime porque, aunque incorpore estructuras artificiales, existe una correspondencia con el dominio público natural en el sentido de que hay una afectación de una categoría de bienes que queda excluido en cuanto tal del grupo de los apropiables por los particulares ${ }^{24}$. Además, el TC ha admitido esta competencia del legislador estatal para demanializar categorías genéricas, en el bien entendido de que la titularidad estatal es independiente de las competencias de gestión (STC 227/1988, FJ 15.º).

En segundo lugar, al apartarse de la LMi, se ha podido calcar la distribución de la Ley 34/1998, de 7 de octubre, del Sector de Hidrocarburos, que en su momento no fue impugnada por las CC. AA. ante el TC. La LHi señala en su artículo 3, sobre “Competencias administrativas”, que:

“2. Corresponde a la Administración General del Estado, en los términos establecidos en la presente Ley: a) Otorgar las autorizaciones de exploración y permisos de investigación a que se refiere el Título II, cuando afecte al ámbito territorial de más de una Comunidad Autónoma. Asimismo, otorgar las concesiones de explotación a que se refiere el citado Título de la presente Ley. b)

\footnotetext{
${ }^{22}$ MOREU CARBONELL, E., Minas: régimen jurídico de las actividades extractivas, Tirant Lo Blanch 2001, p. 102; ARCENEGUI, I., Derecho minero, Civitas, 2002, p. 77.

${ }^{23}$ En el libro clásico de Guaita se explica bien la diferencia de la legislación de minas entre continente y contenido y, sobre todo, que en las minas siempre ha sido de dominio público el lugar, desafectándose el mineral desde el momento de la extracción. GUAITA MARTORELL, A., Derecho administrativo, Aguas, Costas, Minas, 2. ${ }^{\text {a }}$ ed., Civitas, 1986, págs. 232 ss.

24 “Tratándose del 'demanio natural', es lógico que la potestad de demanializar se reserve al Estado en exclusiva y que los géneros naturales de bienes que unitariamente lo integran se incluyan, asimismo, como unidad indivisible en el dominio público estatal [...]. De ahí que sólo el legislador estatal pueda disponer, como condición básica que garantice la igualdad sustancial, la determinación de las categorías de bienes naturales que quedan excluidas del tráfico privado" (STC 227/1988, FJ 14. ${ }^{\circ}$ ). Vid. GÁMEZ MEJÍAS, óp. cit., p. 23, que se refiere a una afectación singular innecesaria.
} 
Otorgar autorizaciones de exploración, permisos de investigación y concesiones de explotación en las zonas de subsuelo marino a que se refiere el Título II de la presente Ley. Asimismo, otorgar las autorizaciones de exploración y permisos de investigación cuando su ámbito comprenda a la vez zonas terrestres y del subsuelo marino".

Acudir al esquema de esta ley no resulta una decisión arbitraria por la vinculación existente entre yacimientos de hidrocarburos y almacenes de $\mathrm{CO}_{2}$ habida cuenta de la posibilidad de utilizar los depósitos ya agotados para confinar $\mathrm{CO}_{2}$. Y, sin duda, la competencia estatal en hidrocarburos legitimaría que el Estado resolviera los conflictos entre usuarios. Distinta puede ser la suerte de proyectar este régimen sobre todo el régimen de permisos y concesiones, sin que se hayan articulado otras técnicas de coordinación más respetuosas con los títulos competenciales específicos.

\subsection{Paradójica aplicación supletoria del reglamento de la Ley de Minas}

Dicho lo anterior, lo que sí resulta paradójico, al instaurar un sistema de fuentes en la materia excesivamente complejo, es que la DF 14 LAGDC declare la supletoriedad del Reglamento General de la Minería (aprobado por Real Decreto 2857/1978, en adelante RGM) a los procedimientos de autorización y concesión tramitados por la Administración general del Estado ${ }^{25}$. Esta disposición ha sido impugnada, aunque solo por la Comunidad Autónoma de Galicia.

No es fácil entender bien el porqué de la DF 14, pues la supletoriedad —y así se dijo en la STC 61/1997- ha de inferirse directamente por el aplicador del derecho. En mi opinión, que haya una remisión expresa (vigente en tanto en cuanto no se desarrolle la LAGDC) solo se debe a la decisión de excluir la aplicación de la LMi, en concreto, la regulación de los depósitos subterráneos de la sección B) (para estos usos basta con autorización administrativa, a otorgar por las comunidades autónomas, sin perjuicio de las reservas que pueda hacer el Estado). Si se hubiera dispuesto que para el uso de los

\footnotetext{
${ }^{25}$ La complejidad deriva de que no es aplicable la LMi; sí que es aplicable su reglamento (a modo de legislación especial de dominio público) y entendemos que solo después de la Ley de Patrimonio por disposición expresa del artículo 3 LAGDC: "Como bienes de dominio público estatal, dichas formaciones geológicas son inalienables, imprescriptibles e inembargables y se regularán, en lo no previsto en esta ley, por lo dispuesto en la Ley 33/2003, de 3 de noviembre, del Patrimonio de las Administraciones Públicas” (el artículo 5.4 LPAP declara que no es de aplicación a los bienes públicos que dispongan de normas especiales).
} 
depósitos con fines de almacenamiento de carbono se aplicarían las reglas de los recursos de la Sección C), donde también se exige concesión administrativa, ello habría dificultado la asunción competencial estatal, porque la gestión de la LMi siempre ha sido autonómica.

Como descartar las reglas de procedimiento del RGM no tendría sentido, se ha optado por incluir esta DF 14, manifestando uno de los puntos más débiles de la decisión estatal de atribuirse las competencias ejecutivas.

Esta remisión al reglamento es importante, además, porque en él se regula la posibilidad de otorgar concesiones directas sin permisos de investigación (algo que admite implícitamente la LAGDC), en el sentido regulado por los artículos 84 y ss. RGM. Y, puesto que ya se conocen los lugares aptos para almacenar carbono, resulta bastante probable que se acuda directamente a estas disposiciones del RGM.

\section{2. ¿Abandono del sistema de reservas de la Ley de Minas?}

Descartar la aplicación de la LMi tiene otra consecuencia, que consiste en que el Estado ha decidido no utilizar para el almacenamiento geológico la figura de las reservas demaniales del artículo 7 de la Ley de Minas, tal y como se había hecho en varias ocasiones $^{26}$.

Para que se comprenda el alcance de la anterior afirmación, cabe recordar que un régimen de reservas permitía a la Administración convocar concursos para seleccionar al concesionario. Y, si la LMi no es de aplicación, es discutible que pueda utilizarse este

\footnotetext{
${ }^{26}$ Salvo error en la búsqueda por mi parte, en el BOE se habían publicado 3 reservas a favor del Estado para almacenes de dióxido de carbono:

1) Resolución de 4 de marzo de 2008, de la Dirección General de Política Energética y Minas, por la que se publica la inscripción de propuesta de reserva provisional a favor del Estado para recursos de la sección B), estructuras subterráneas susceptibles de ser un efectivo almacenamiento de dióxido de carbono, en el área denominada “Almacén 10”, comprendida en la provincia de Huelva.

2) Real Decreto 1999/2009, de 11 de diciembre, por el que se dispone la declaración de zona de reserva provisional a favor del Estado para exploración de recursos de la sección B), estructuras subterráneas susceptibles de ser un efectivo almacenamiento de dióxido de carbono, en el área denominada "Asturias Centro", comprendida en la provincia de Asturias y parte de la plataforma continental costera (se otorgó por el plazo de un año y no se ha publicado la orden de prórroga).

3) Real Decreto 1733/2010, de 17 de diciembre, por el que se dispone la declaración de zona de reserva provisional a favor del Estado para la investigación y eventual explotación de recursos de la sección B), estructuras subterráneas susceptibles de ser un efectivo almacenamiento de dióxido de carbono, en el área denominada “Almacén 3”, comprendida en la provincia de Palencia (vigente por tres años).
} 
instrumento ya que faltaría la imprescindible habilitación normativa, que ha de contenerse en una norma con rango de ley, de acuerdo con el artículo 132 CE.

Y entiendo que no cabe utilizar la figura de la reserva demanial porque la LAGDC no la regula y, de acuerdo con la doctrina más especializada, la previsión del artículo 104 de la LPAP (aplicable supletoriamente) solo sirve cuando se trate de bienes de "uso público”, lo que claramente no es el caso de las estructuras subterráneas ${ }^{27}$. Es decir, la nueva regulación no permitiría acudir a las reglas relativas a las reservas del RGM, que en desarrollo de la LMi prevé la convocatoria de concursos tras el establecimiento de una reserva. Sin reserva, rige el principio de concesión rogada, esto es, otorgada tras la solicitud de un particular.

Esta decisión resulta, a mi juicio, incomprensible dado que supone despreciar la utilidad de una figura tradicional para la gestión de bienes públicos y que en modo alguno obliga al Estado a aplicarla. Es decir, lo incomprensible es que no se recoja esta figura, aspecto que es independiente de que, con la entrada en vigor de la LAGDC, el Estado haya decidido retirarse de todas las reservas hechas a su favor anteriormente y deje los proyectos concretos emprendidos en manos de sus socios privados (cfr. DT 2 LAGDC). De haberse habilitado las reservas, el Estado habría podido intervenir facilitando, en su caso, las inversiones privadas cuando efectivamente concurrieran razones estratégicas para impulsar un almacén concreto ${ }^{28}$.

Y además en este punto no se habría producido ningún conflicto competencial, dado que la intervención singular del Estado sobre este dominio público preferentemente

\footnotetext{
${ }^{27}$ La aplicación supletoria de la LPAP no es suficiente, por más que aquí se recoja una regulación de la figura de las reservas (art. 104) que exige acuerdo previo del Consejo de Ministros e inscripción en el Registro de la Propiedad. Según ha explicado BARCELONA LLOP, J. (que se ha planteado el problema en relación con los montes), la LPAP restringe su uso cuando se trata de bienes destinados al uso general ("Utilización de los bienes y derechos destinados a un servicio público", en Chinchilla Marín, C. [coor.], Comentarios a la Ley 33/2003, del Patrimonio de las Administraciones Públicas, Thomson-Civitas, Madrid, 2004, pp. 554-556). A este argumento habría que añadir que habiendo una ley especial (LAGDC) en la que se opta ampliamente por la iniciativa privada, ¿no se está descartando con ello (acaso de manera implícita) la intervención pública a través de reservas?

${ }^{28}$ De nuevo el abandono del esquema de la Ley de Minas a favor de la Ley de Hidrocarburos puede tener que ver con esto, aunque haya determinado otra consecuencia relevante. Como explica MOREU CARBONELL, E., Minas..., cit, p. 275, la LHi no regula reservas, resultando, por ello y paradójicamente, más intervencionista que la LMi, pues aunque en aquella no se regule la reserva tradicional caracterizada por su singularidad (se proyectaba sobre un yacimiento, etc.), se señala que la explotación siempre será de gestión indirecta, lo que conlleva una reserva de actividad (aunque la Ley prohíba para hidrocarburos la gestión propia o directa). Esta última idea no está, sin embargo, en la LAG puesto que aquí se sigue el sistema de concesión rogada (por más que en el procedimiento de otorgamiento exista una tramitación en competencia de proyectos).
} 
afectado al uso privativo por particulares (previa solicitud de concesión) podría legitimarse sobre el artículo 149.1.24. ${ }^{\circ} \mathrm{CE}$ (obras públicas de interés general), pues la adecuación de un depósito subterráneo es la transformación de un inmueble demanial y reviste, por lo tanto, el carácter de “obra”29. Este enfoque sería más respetuoso con las competencias autonómicas, pues conllevaría que, en general y para los casos no reservados, la concesión también sería competencia de la comunidad autónoma (sin perjuicio de los controles de legalidad que con carácter general corresponden al Estado). Habida cuenta de que los depósitos son públicos (las formaciones geológicas son en todo caso de dominio público, según el artículo 3 LAGDC) y que la responsabilidad final es pública, no tendría que haber habido ningún inconveniente en utilizar esta competencia, que es propiamente de ejecución. En derecho español el concepto de “obra” tiene un doble significado, pues abarca tanto las operaciones de transformación material como el resultado. Y no hay duda de que los almacenes son una obra o una instalación que pueden ser también de interés general del Estado. Que exista una utilización privada por parte de un concesionario no repugna en absoluto al concepto de obra $^{30}$.

Esta perspectiva queda reforzada si recordamos que en el almacenamiento existe otra dimensión, que es la relativa a la construcción de redes subterráneas de transporte de $\mathrm{CO}_{2}$ y que también está por regular en España ${ }^{31}$.

\footnotetext{
${ }^{29}$ Se ha escrito mucho sobre el alcance de la competencia estatal sobre obras públicas. Da cuenta del estado de la doctrina, ESCARTIN ESCUDÉ, V., El periurbanismo estatal. La ordenación urbanística del dominio público del Estado, Marcial Pons, 2009, pp. 76 ss. En esta monografía se mantiene la tesis, que aquí aplicamos, de que el título del apartado 24 sirve tanto para materias sobre las que el Estado tenga competencias como para declarar cualquier tipo de obra de su interés; por lo tanto, al margen de que, en general, esa materia sea de competencia autonómica o local.

${ }^{30}$ El criterio elaborado por T. R. FERNÁNDEZ RODRÍGUEZ en su clásico e influyente artículo ("Las Obras Públicas”, Revista de Administración Pública, 100-102 (1983), vol. II, pp. 2427 y ss.) presupone que son obras de dominio público o sobre el dominio público ("transformación de un inmueble demanial”). En nuestro caso, además, la responsabilidad de la obra será finalmente estatal, por lo que cabría hablar de reversión al Estado. En la jurisprudencia constitucional, la STC 56/1986 vincula las obras que pueda promover el Estado al artículo 149.1.24 CE, sin exigir que sean de dominio público. Como veremos más abajo, las prerrogativas estatales para facilitar el encaje urbanístico de infraestructuras no se conectan a obras de titularidad del Estado, sino solo de interés público. El tema de la propiedad en concesiones de dominio o servicios públicos (si es propiedad a término del concesionario o no) ha sido, por lo demás, objeto de atención por la doctrina desde siempre (ARIÑO ORTIZ, G., "La afectación de bienes al servicio público", reeditado recientemente en Lecciones de Administración y políticas públicas, Iustel, 2011, pp. 655 ss.), aunque ahora recobre importancia en el contexto de las nuevas figuras concesionales (o también de los contratos de colaboración público-privada) en cuanto al uso de indicios de los que se desprenda que se ha transferido parte del riesgo al contratista.
}

${ }^{31}$ Aunque de momento la Directiva no entra en este aspecto, que aún parece más futurista que los almacenes de $\mathrm{CO}_{2}$, ni es previsible que lo haga en el futuro, porque se relega a las legislaciones 


\section{Urbanismo y almacenes de $\mathrm{CO}_{2}$}

\subsection{Concesiones y permisos urbanísticos}

Las leyes estatales relativas a infraestructuras de interés general suelen incorporar reglas específicas para facilitar su encaje en la ordenación territorial y urbanística. Y la LAGDC no es una excepción. Las reglas que contiene al respecto solo han sido objetadas por la Comunidad Autónoma de Galicia. En concreto, forma parte del objeto de su recurso el artículo 28.4 que dispone que:

“4. Las Administraciones públicas tendrán en cuenta los registros a que se refiere este artículo en sus procedimientos de planificación, así como cuando autoricen actividades susceptibles de afectar o verse afectadas por el almacenamiento geológico de $\mathrm{CO}_{2}$ en los lugares de almacenamiento registrados. A este respecto, habrá de observarse lo previsto en la disposición adicional primera de esta ley”.

En este artículo podemos encontrar dos partes distintas La primera, que no afecta a lo competencial, es una mera trasposición (una copia literal) del artículo 25.2 de la Directiva, según el cual los almacenamientos ya autorizados y, por lo tanto, con habilitación urbanística ${ }^{32}$ han de tenerse en cuenta en los planes urbanísticos y, en general, en las autorizaciones que puedan estar relacionadas con ellos.

nacionales, hay autores que destacan que la legislación comunitaria no ha considerado suficientemente la vinculación entre las redes de transporte de $\mathrm{CO}_{2}$ (redes embrionarias en un primer momento por cuanto supondrán únicamente redes de acceso o vías de llegada a almacenes y no una red de transporte en sentido propio, puesto que esta exigiría interconexión entre distintos almacenes) y otras redes energéticas (en particular, las del gas natural, que incluso pueden utilizarse con esta finalidad para yacimientos agotados de gas natural reciclados en almacenes de $\mathrm{CO}_{2}$ ) que gozan de características prácticamente iguales, siendo la problemática jurídica idéntica. Vid. ROGGENKAMP, M.M. y HAAN-KAMMINGA, A., " $\mathrm{CO}_{2}$ transportation in the European Union: can the Regulation of $\mathrm{CO}_{2}$ Pipelines Benefit from the Experiences of the Energy Sector?”, Carbon Capture and Storage, emerging legal and regulatory issues, ed. por HAVERCORFT, I., MARCRORY, R. y STEWART, R.B., Hart Publishing, Oxford, 2011, pp. 107 ss. En la p. 116 indican que las soluciones dominicales aplicadas a los gaseoductos (propiedad estatal, privada o público-privada) pueden trasladarse a las redes y que la Directiva deja esta opción en manos de los Estados.

32 Sería conveniente que en el Registro se anotaran las concesiones ya otorgadas y, por lo tanto, las que ya hubiesen superado la tramitación urbanística. Esto es así porque, aunque el artículo 90 RGM, que regula la inscripción en el Registro, no dice nada sobre la compatibilidad urbanística previa, esta se desprende del artículo 3 RGM y de la legislación básica de régimen local (arts. 58.2 y 84.3 de la LRBRL), como muy bien ha explicado MOREU CARBONELL, E., "Las minas", en Lecciones y materiales para el Estudio del derecho administrativo, tomo V, Bienes e Infraestructuras públicas (CANO CAMPOS, coord.), Iustel, 2009, p. 201 (artículo 3 RGM: "No podrán abrirse calicatas, efectuar sondeos ni hacerse labores mineras a distancia menor de cuarenta metros de edificios, ferrocarriles, puentes o conducciones de agua; a menos de las distancias áticas que establezcan las leyes sobre carreteras, autovías y autopistas; a menos de cien metros de alumbramientos, canales, acequias y abrevaderos o fuentes públicas; ni dentro de los perímetros de protección de baños o aguas minero-medicinales o minero-industriales o termales, y recursos geotérmicos; a menos de 1.400 metros de los puntos fortificados, a no ser que en éste en último caso se obtenga licencia de la autoridad militar, y en los otros de la autoridad que corresponda, si se trata 
La segunda parte ya no traspone la Directiva, pues bajo la remisión a la DA 1. ${ }^{\text {a }}$ LAGDC se contiene un mecanismo para conseguir la compatibilidad urbanística de almacenes aún no autorizados. Y entendemos que no traspone la Directiva porque esta no prejuzga la facultad de las autoridades nacionales para ordenar el uso del suelo (art. 4 Dir.).

La disposición adicional primera, que también se incluye en el recurso de Galicia, lleva la rúbrica “concesiones de almacenamiento y planeamiento” y señala lo siguiente:

“1. Las concesiones de almacenamiento de $\mathrm{CO}_{2}$ deberán tenerse en cuenta en los correspondientes instrumentos de ordenación del territorio, de ordenación urbanística o de planificación de infraestructuras viarias según corresponda, precisando las posibles instalaciones, calificando adecuadamente los terrenos y estableciendo las reservas de suelo necesarias para la ubicación de las nuevas instalaciones y la protección de las existentes.

2. En los casos en los que no se haya tenido en cuenta las concesiones de almacenamiento de $\mathrm{CO}_{2}$ en instrumentos de ordenación o de planificación descritos en el apartado anterior, o cuando razones justificadas de urgencia o excepcional interés aconsejen el establecimiento de instalaciones para el almacenamiento, y siempre que en virtud de lo establecido en otras leyes resultase preceptivo un instrumento de ordenación del territorio o urbanístico, según la clase del suelo afectado, se estará a lo dispuesto en la legislación sobre régimen del suelo y ordenación del territorio que resulte aplicable, y en particular, a lo establecido en la disposición adicional décima del Real Decreto Legislativo 2/2008, de 20 de junio, por el que se aprueba el texto refundido de la Ley del Suelo.

3. Las restricciones previstas en los instrumentos de ordenación o de planificación descritos en el apartado anterior que afecten a las actividades de investigación y aprovechamiento de estructuras subterráneas para el almacenamiento de $\mathrm{CO}_{2}$ no podrán tener carácter genérico y deberán estar motivadas.

4. En el caso de almacenamiento de $\mathrm{CO}_{2}$ en el subsuelo marino se estará a lo dispuesto en la disposición adicional tercera”.

Aunque este precepto puede diseccionarse en varios apartados, la tónica común es que está ideado para que concesiones ya otorgadas superen la compatibilidad urbanística. A esto se refieren el apartado 1 ("las concesiones deberán tenerse en cuenta [en los planes

de obras y servidumbres públicas, o del dueño, cuando se trate de edificios o derechos de propiedad particular"). 
de uso de suelo], calificando adecuadamente los terrenos y estableciendo las reservas necesarias”) y también —o sobre todo- el apartado 2, que prevé la aplicación del régimen privilegiado para la autorización de obras de interés general del Estado en casos de concesiones de almacenamiento ${ }^{33}$.

No podemos dejar de comentar que este aspecto, impugnado únicamente por Galicia, resulta muy curioso, y no tanto por el problema competencial planteado, sino por la excepcionalidad que supone desde la perspectiva urbanística. Y es que, salvo error por mi parte, es el primer caso de instalación cuya autorización no se subordina a la compatibilidad urbanística previa, contradiciendo de esta manera el régimen general de la Ley de Minas, que ha sido muy bien analizado por MOREU CARBONELL ${ }^{34}$. Al respecto, y para resaltar la originalidad de la Ley, cabe recordar que para otras actividades contaminantes el artículo 12.1.b) de la Ley 16/2002, de 1 de julio, de Prevención y Control Integrados de la Contaminación, exige, como trámite previo para la presentación de solicitudes de actividades sujetas a su ámbito de aplicación, el certificado de que el planeamiento urbanístico admite o acepta ese tipo de uso. Sin embargo, aquí se invierte la regla general, puesto que la Ley establece de manera imperativa e inequívoca la obligatoriedad para los planes de admitir el uso del subsuelo y del suelo supraestante para las instalaciones que resulten necesarias.

\subsection{La limitada competencia autonómica para prohibir almacenes en zonas de su territorio}

En este contexto, además, hay que interpretar la previsión del apartado 3 de la disposición adicional 1, según la cual:

“3. Las restricciones previstas en los instrumentos de ordenación o de planificación descritos en el apartado anterior que afecten a las actividades de investigación y

\footnotetext{
${ }^{33}$ El procedimiento de la DA 10. ${ }^{\text {a }}$ del TRLS (que es la versión vigente del artículo 180.2 TRLS 76 o 244.2 TR92: exención de licencia en obras promovidas por el Estado) consiste en que el Estado remitirá el proyecto al Ayuntamiento para que en el plazo de un mes manifieste su disconformidad con la ordenación urbanística; en caso de disconformidad, y tras oír a la Comunidad Autónoma, el Consejo de Ministros podrá ordenar la iniciación del procedimiento para alterar el planeamiento y conseguir la compatibilidad urbanística. La disposición adicional 10 del TRLS se ha dictado sobre las competencias del artículo 149.1 apartados 8 (legislación civil) y 18 CE (bases sobre el régimen jurídico de las administraciones públicas), pero no sobre el artículo 149.1.24, que sería su lugar lógico dado que se refiere a obras promovidas por la AGE.

${ }^{34}$ Véase nota Error! No s'ha definit el marcador..
} 
aprovechamiento de estructuras subterráneas para el almacenamiento de $\mathrm{CO}_{2}$ no podrán tener carácter genérico y deberán estar motivadas”.

Bajo esta disposición se encuentra la respuesta a un interrogante planteado en Alemania: ¿podría una comunidad autónoma prohibir almacenes en su territorio? ${ }^{35}$

Sin embargo, no es fácil la interpretación de esta DA 1, que traslada la regla contenida en el artículo 122 de la Ley de Minas ${ }^{36}$. Por una parte, parecería permitir que las comunidades autónomas o municipios prohibiesen en partes de su territorio este tipo de uso. Pero, por otra, y al remitirse al apartado anterior, lo que realmente dice es que esas restricciones podrán ser enervadas por decisión de la Administración general del Estado. En relación con la selección de lugares, esta opción del legislador también muestra esa trasposición tan plana de la Directiva. Aquí, si el Estado hubiera tenido algún interés por la materia, se podría haber optado por otro tipo de regulación. En este sentido se ha pronunciado GÁMEZ MEJÍAS, que indica que “resulta poco lógico que el legislador español no prevea de ningún modo algún tipo de planificación en la materia que permita ordenar las futuras instalaciones y la gestión de las mismas”, más aún si se tiene en cuenta que existe un estudio del IGME cuyos resultados provisionales identificaban más de 100 estructuras disponibles ${ }^{37}$.

\section{CONCLUSIONES}

Es indiscutible que la regulación de cómo se ha de almacenar carbono importa a la protección del medio ambiente y, de hecho, la Directiva comunitaria se apoyó en esta competencia (antiguo artículo 175.1 TCE). Sin embargo, a diferencia de la regulación nacional, lo que hace esta norma es establecer un mecanismo voluntario para los Estados de mitigación de emisiones de $\mathrm{CO}_{2}$ y, en este sentido, encaja en la política

\footnotetext{
${ }^{35}$ En el trabajo de KRÄMER, ya citado (p. 14), se analiza lo que ha sucedido en Alemania, donde inicialmente se atribuyó a los Länder esta posibilidad. También este mismo autor señala que en España acaso se trate de un aspecto sobre el que pueda pronunciarse el TC ("Case studies on the implementation of Directive 2009/31/EC on the geological storage of carbon dioxide: Spain”, University College London, Centre for Law and Environment, Carbon Capture Legal Programme, noviembre 2011, p. 5).

${ }^{36}$ El artículo 122 de la Ley de Minas, introducido en 2007, dice: "Cualquier prohibición contenida en los instrumentos de ordenación sobre actividades incluidas en la Ley de Minas deberá ser motivada y no podrá ser de carácter genérico”.

${ }^{37}$ Vid. KRAMER, L., "Case studies on the implementation of Directive 2009/31/EC on the geological storage of carbon dioxide: Spain”, cit., que recoge el estudio del IGME, que identificó 103 estructuras con una capacidad total de 13,4 Gt (www.igme.es/internet/sistemas_infor/ConsultaSID/presentacion.asp?ID=140531).
} 
(medioambiental) de cambio climático. Más aún, al margen del peso de consideraciones energéticas (seguir consumiendo carbón europeo solo será posible si las altas emisiones de $\mathrm{CO}_{2}$ que provoca no se computan en los totales nacionales, que ya están sujetos a contingentes), la Directiva se ha redactado mirando muy de cerca a la opinión pública europea y tratando de salvar las suspicacias de asociaciones ecologistas.

Para estas, la captura de $\mathrm{CO}_{2}$ es una excusa para atrasar el cambio hacia el uso de energías renovables y, además, se subraya la incertidumbre científica en relación con los riesgos ambientales de esta nueva actividad (en particular, no se sabe cuál va a ser la afectación a las aguas subterráneas). Por eso, en la Directiva importa - y mucho— la perspectiva medioambiental (recordemos que su artículo 4.1 permite a los Estados prohibir totalmente el almacenamiento en su territorio). Esto es, la sujeción a control público de la captura de carbono (la Directiva presta atención especial a los requisitos técnicos de los espacios seleccionados como almacenes y sobre todo a las cautelas para asegurar el sellado al término de la actividad).

La perspectiva estatal es muy diferente, porque la regulación tiene que decidir, en primer lugar, si va a admitir total o parcialmente en su territorio esta técnica, y, después, si va a endurecer las condiciones ambientales y señalar qué autoridad es competente. En España, por razones estratégicas se ha optado por aceptar la técnica (no hay muchas más opciones para apoyar al carbón nacional) y no endurecer los requisitos ambientales. Pero, además, y este es el paso adicional que no encaja en lo competencial, el Estado se reserva la autorización singular de almacenes (concesiones) previo informe de la Comunidad Autónoma, cuando todos los aprovechamientos de la legislación de minas corresponden a las comunidades autónomas.

En mi opinión, dado que las concesiones de almacenes encajan en minas, que parece su "lugar natural” por utilizar recursos de la sección B) ${ }^{38}$, la asunción de competencia estatal no se justifica desde la Constitución y resulta desproporcionada. La desproporción derivaría, en este caso, de que existen muchas alternativas para regular esta materia que permitirían alcanzar los mismos fines y que resultarían más respetuosas con las competencias de ejecución autonómicas.

\footnotetext{
${ }^{38}$ Cfr., sin embargo, KRÄMER, óp. cit. (Spain), p. 14, que defiende que es medio ambiente, señalando que si el TC no considerase ajustado a la CE esta competencia estatal, las CC. AA. deberían poder prohibir los almacenes en su territorio.
} 
Aparte de la confusión entre títulos competenciales, hay otra cuestión que acaso no sea nunca apreciada por el TC, que es el perjuicio que supone al principio constitucional de eficacia la intervención de cuatro órganos administrativos con una atribución de responsabilidades aparentemente diferenciadas pero parcialmente concurrentes. A mi juicio, se rozan los límites del artículo 9.3 CE, que proscribe "la arbitrariedad de los poderes públicos”. Pues ¿no es arbitraria una regulación que instaura un sistema de colaboración interadministrativa excesivamente complejo cuando su finalidad declarada es facilitar las inversiones privadas?

\section{BIBLIOGRAFÍA}

ALENZA GARCÍA, J. F., “El nuevo régimen legal del almacenamiento geológico del dióxido de carbono”, Revista de Administración Pública, núm. 185, (2011).

ARCENEGUI, I., Derecho minero, Civitas, 2002.

ARIÑO ORTIZ, G., Lecciones de Administración y políticas públicas, Iustel, 2011.

CARO-PATON, I., El mercado de derechos a contaminar. Régimen jurídico-público del mercado comunitario de derechos de emisión en España, vol. col. dir. por SANZ RUBIALES, I., Lex Nova, 2007.

ESCARTIN ESCUDÉ, V., El periurbanismo estatal. La ordenación urbanística del dominio público del Estado, Marcial Pons, 2009.

FERNÁNDEZ RODRÍGUEZ, T. R., “Las Obras Públicas”, Revista de Administración Pública, 100-102 (1983), vol. II.

GÁMEZ MEJÍAS, M., “El marco jurídico del almacenamiento geológico profundo de dióxido de carbono en el contexto de la lucha contra el cambio climático. Perspectivas y reflexiones tras la trasposición al derecho interno”, Revista Aranzadi de Derecho Ambiental, 20 (2011).

GUAITA MARTORELL, A., Derecho administrativo, Aguas, Costas, Minas, 2. ${ }^{a}$ ed., Civitas, 1986.

IGME (ZAPATERO RODRÍGUEZ, M. A., director), "Proyecto Europeo Geocapacity. Assessing European capacity for geological storage of carbon dioxide” ("Estimación de 
la capacidad europea para el almacenamiento de $\mathrm{CO}_{2}$. Caso español”), 2009 (www.igme.es/internet/sistemas_infor/ConsultaSID/presentacion.asp?ID=140531).

KRÄMER, L., "Case studies on the implementation of Directive 2009/31/EC on the geological storage of carbon dioxide: Germany”, Carbon Capture Legal Programme, University College London, Faculty of Laws, Centre for Law and Environment, 2011 (www.ucl.ac.uk/cclp).

MOREU CARBONELL, E., Minas: régimen jurídico de las actividades extractivas, Tirant Lo Blanch, 2001.

MOREU CARBONELL, E., “Las minas”, en Lecciones y materiales para el Estudio del derecho administrativo, tomo V, Bienes e Infraestructuras públicas (CANO CAMPOS, coord.), Iustel, 2009.

ROGGENKAMP, M.M. y HAAN-KAMMINGA, A., " $\mathrm{CO}_{2}$ transportation in the European Union: can the Regulation of $\mathrm{CO}_{2}$ Pipelines Benefit from the Experiences of the Energy Sector?”, Carbon Capture and Storage, emerging legal and regulatory issues, ed. por HAVERCORFT, I., MACRORY, R. y STEWART R.B., Hart Publishing, Oxford, 2011.

SANZ RUBIALES, I., "El almacenamiento geológico de dióxido de carbono en la directiva 2009/31, de 31 de abril”, Revista Aranzadi de Derecho Ambiental, núm. 19 (2011). 


\section{TABLA DE PRECEPTOS IMPUGNADOS POR LAS COMUNIDADES AUTONOMAS}

A: Aragón; C: Cataluña; G: Galicia

MI: Ministerio de Industria; MMA: Ministerio de Medio Ambiente

\begin{tabular}{|c|c|c|c|c|}
\hline $\begin{array}{l}\text { Art. } 1.3 \\
\text { Desarrollo reglamentario } \\
\text { para la determinación de } \\
\text { requisitos para redes } \\
\text { auxiliares de transporte y } \\
\text { otras instalaciones. } \\
\text { A }\end{array}$ & $\begin{array}{l}\text { Art. } 3 \\
\text { Pertenencia al } \\
\text { dominio público } \\
\text { estatal de } \\
\text { formaciones } \\
\text { geológicas. } \\
\text { G y A }\end{array}$ & $\begin{array}{l}\text { Art. } 5 \\
\text { Atribución } \\
\text { competencias a MI y } \\
\text { MMA } \\
\text { (también se impugnan } \\
\text { los preceptos que } \\
\text { desarrollan los listados } \\
\text { del artículo- 5). } \\
\text { G y A: 5; C: 5, } \\
\text { apartados 1, } 2 \text { y } 4\end{array}$ & $\begin{array}{l}\text { Art. 6, apdos. } 3 \text { y } 4 \\
\text { Solución de } \\
\text { conflictos entre } \\
\text { peticiones de } \\
\text { almacenamiento. } \\
\text { C }\end{array}$ & $\begin{array}{l}\text { Art. 8.-6 2. párr. } \\
\text { Remisión del } \\
\text { resultado de los } \\
\text { trabajos de } \\
\text { investigación al MI. } \\
\text { G, C y A }\end{array}$ \\
\hline
\end{tabular}

Compefencias estatales para otorgar permisos de investigación interautonómicos $\mathrm{y}_{2}$ sobre todo, concesiones de aprovechamiento

\begin{tabular}{|c|c|c|c|c|}
\hline $\begin{array}{l}\text { Art. 9, } \text { apdos. } 6 \text { y } 7 \\
\text { Reglas procedimentales } \\
\text { para el otorgamiento de } \\
\text { los permisos de } \\
\text { investigación de } \\
\text { competencia } \\
\text { (formaqiones que afecten } \\
\text { a variag CC.AA.). } \\
\text { G, C y A }\end{array}$ & $\begin{array}{l}\text { Art. 10, apdos. 4, } 6 \\
\text { y } 7 \\
\text { Distintas reglas } \\
\text { sustantivas sobre la } \\
\text { concesión de } \\
\text { almacenamiento } \\
\text { por MI. } \\
\text { G, C y A }\end{array}$ & $\begin{array}{l}\text { Art. } 11 \\
\text { Reglas procedimentales } \\
\text { para la concesión de } \\
\text { almacenamiento por } \\
\text { MI. } \\
\text { G: 11; C y A: 11, } \\
\text { apartados } 1,2 \text { y } 6\end{array}$ & 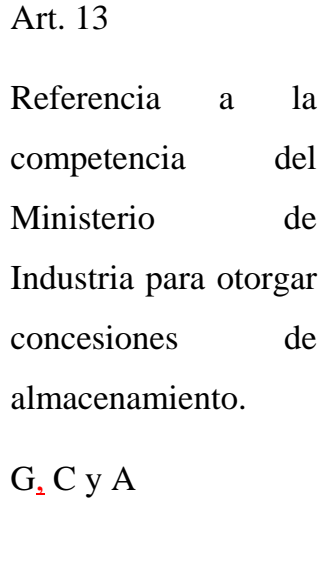 & 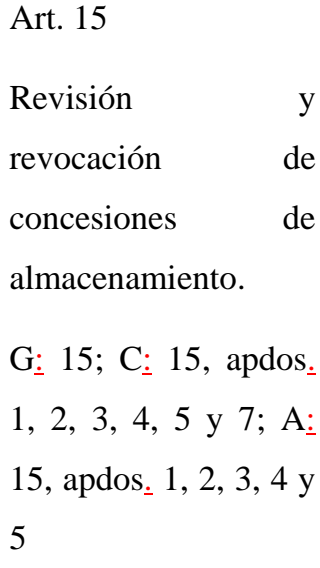 \\
\hline \multicolumn{4}{|c|}{ Competencias estatales tras el cierre de depósitos } & \\
\hline $\begin{array}{l}\text { Art. 19 } \mid \text { apdos. } 2 \text { y } 3 \\
\text { Competencias del } \\
\text { Ministerio de industria } \\
\text { sobre “plan de } \\
\text { seguimiento". } \\
\text { G, C y A }\end{array}$ & $\begin{array}{l}\text { Art. } 23 \\
\text { Obligaciones } \\
\text { relativas al cierre } \\
\text { exigibles por el MI } \\
\text { y MA (23.5). } \\
\text { G y C: 23; A: } 23 \\
\text { apdos. 1, } 2 \text { y } 3\end{array}$ & $\begin{array}{l}\text { Art. } 24 \\
\text { Transferencia de } \\
\text { responsabilidad al } \\
\text { Estado tras el cierre. } \\
\text { G: 24; C: 24, apdos. 1, } \\
\text { 2, } 3 \text { у } 4\end{array}$ & $\begin{array}{l}\text { Art. } 25 \\
\text { Seguimiento de } \\
\text { almacenes cerrados. } \\
\text { G y C }\end{array}$ & \\
\hline $\begin{array}{l}\text { Art. 26, apdos. 1, 3, } 4 \text { y } 5 \\
\text { Competencias MI para }\end{array}$ & $\begin{array}{l}\text { Art. } 27 \\
\text { Competencias MI }\end{array}$ & $\begin{array}{l}\text { Art. 28, apdo. } 4 \text { (en } \\
\text { relación con DA } 1_{\check{\sim}}^{\mathrm{a}} \text { ) }\end{array}$ & $\begin{array}{l}\text { Art. } 38 \\
\text { Competencia }\end{array}$ & $\begin{array}{l}\text { DA 2. } \\
\text { Determinación }\end{array}$ \\
\hline
\end{tabular}




\begin{tabular}{|c|c|c|c|c|}
\hline $\begin{array}{l}\text { ordenar el acceso de } \\
\text { terceros a redes de } \\
\text { transporte y/o almacenes. } \\
\text { G, C y A }\end{array}$ & $\begin{array}{l}\text { para la solución de } \\
\text { conflictos sobre } \\
\text { acceso de terceros. } \\
\text { G y A: 27; C: } 27 \text {, } \\
\text { apdo. } 1\end{array}$ & $\begin{array}{l}\text { Obligación de los } \\
\text { planes urbanísticos de } \\
\text { considerar los registros } \\
\text { de almacenes. } \\
\text { G }\end{array}$ & 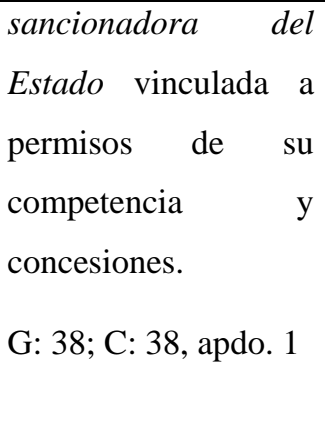 & $\begin{array}{l}\text { MI del cumplimiento } \\
\text { de obligaciones } \\
\text { legales de } \\
\text { instalaciones de } \\
\text { combustión de más } \\
\text { de } 300 \text { megavatios. } \\
\text { G }\end{array}$ \\
\hline $\begin{array}{l}\text { DA 3. } \\
\text { Atribución de todas las } \\
\text { competencias (incluido } \\
\text { permiso) } \\
\text { almacenamiento } \\
\text { subsuelo marino. } \\
\text { G: DA 3.; C: DA 3. } \\
\text { apdo. } 5\end{array}$ & $\begin{array}{l}\text { DT 1. } \\
\text { Atribución a MI de } \\
\text { competencias para } \\
\text { adecuación de } \\
\text { instalaciones } \\
\text { preexistentes-. } \\
\text { A }\end{array}$ & $\begin{array}{l}\text { DF 11. } \\
\text { Atribución de carácter } \\
\text { básico a determinados } \\
\text { preceptos. } \\
\text { G, C y A }\end{array}$ & $\begin{array}{l}\text { DF 14. } \\
\text { Aplicación supletoria } \\
\text { del reglamento de } \\
\text { minas para } \\
\text { concesiones } \\
\text { otorgadas por el } \\
\text { Estado. } \\
\text { G }\end{array}$ & \\
\hline
\end{tabular}

